\title{
La reserva de ley en el ámbito tributario local: una reflexión en torno a la Ley de Tasas Estatales y Locales y de Reordenación de las Prestaciones Patrimoniales de Carácter Público
}

\author{
Santiago A. Bello Paredes \\ Profesor Titular Interino de Derecho Administrativo \\ Universidad de Burgos
}

\begin{abstract}
Sumario: I. INTRODUCCIÓN. II. CONCEPTO Y SIGNIFICADO DEL PRINCIPIO DE RESERVA DE LEY EN EL ÁMBITO TRIBUTARIO LOCAL: A. Referencia al origen del concepto de reserva de ley. B. Corrección del alcance y significado tradicional de este principio constitucional en el ámbito tributario local. III. DETERMINACIÓN DEL ÁMBITO DE DISCUSIÓN: SOBRE LA UBICACIÓN Y EFECTOS DE LA LEY 25/1998, DE 13 DE JULIO, EN RELACIÓN AL PRINCIPIO DE RESERVA DE LEY: A. El ámbito de actuación de la reserva de ley tributaria en esta norma. B. La relación interordinamental en materia de tasas locales. IV. A MODO DE CONCLUSIÓN.
\end{abstract}

\section{INTRODUCCIÓN}

La publicación de la Ley 25/1998, de 13 de julio, de modificación del Régimen legal de las Tasas Estatales y Locales y de Reordenación de las Prestaciones Patrimoniales de Carácter Público ${ }^{1}$, ha vuelto a plantear de nuevo el problema aún no resuelto en nuestro Derecho positivo en torno a la configuración del principio constitucional de reserva de ley en el ámbito tributario de las Entidades locales.

Si éste es un problema «abierto» en la doctrina de nuestro país ${ }^{2}$, lo es mucho más en el ámbito del Derecho positivo, por cuanto, ante diversas actuaciones legislativas estatales regulando la materia tributaria local, se han producido declaraciones del Tribunal Constitucional que han

\footnotetext{
$1 B O E$ de fecha 14 de julio de 1998.

${ }^{2}$ Como resulta de las constantes aportaciones que sobre este tema se realizan; así, J. Ferreiro LAPATZA, «La Hacienda local. Antecedentes históricos y situación actual. El marco constitucional», Tratado de Derecho Financiero y Tributario local, Madrid, 1993, pp. 49 y ss.; A. MenÉnDEZ MORENO, «Algunas reflexiones sobre los principios de capacidad y legalidad de los precios públicos», Estudios de Derecho Tributario en memoria de Maria del Carmen Bollo Arocena, Bilbao, 1993, pp. 29 y ss., o en un trabajo anterior, «El poder tributario de las Corporaciones locales», Organización Territorial del Estado (Administración local), vol. III, Madrid, 1985, pp. 2097 y ss.; J. Ramallo Massanet, «La reordenación de los precios públicos locales», REALA n. ${ }^{\circ} 268,1995$, pp. 805 y ss.
} 
tendido, casi de manera indefectible, a minorar la posibilidad de actuación local en este sector ${ }^{3}$, situación jurisprudencial que se ha visto modificada, en alguna medida, por la Sentencia de este Tribunal de fecha 16 de diciembre de $1999^{4}$ en la que se declara la constitucionalidad de la Ley de Haciendas Locales ${ }^{5}$, en su redacción de fecha 28 de diciembre de 1988.

${ }^{3}$ Así, cabe recordar las Sentencias del Tribunal Constitucional de fechas 15 de diciembre de 1985 y 17 de febrero de 1987, que declaran inconstitucionales diversos preceptos de la Ley 24/1983, de 21 de diciembre, de medidas urgentes de saneamiento de las Entidades locales, que establecían la posibilidad de las Entidades locales de imponer recargos y tipos de gravamen a su favor en el impuesto estatal del IRPF. Esta situación contrasta con la jurisprudencia dictada por los Tribunales de lo contencioso en relación con la impugnación concreta de actuaciones normativas locales en materia de tasas y precios públicos; de esta suerte, el Tribunal Supremo acepta que en materia local la formulación del principio de reserva de ley sea «más flexible» (Sentencia de fecha 9 de julio de 1997, en la que se acepta la legalidad del contenido del artículo 24 de la Ley de Haciendas Locales de 1988, que permitía la fijación de la cuantía de las tasas locales con una gran discrecionalidad por los municipios), y ello hasta el punto de considerar que «las Ordenanzas son, pues, claras manifestaciones de la potestad reglamentaria municipal, pero no son reglamentos absolutamente equiparables a los estatales o autonómicos en materia tributaria, habida cuenta de las modulaciones que las propias leyes, fundamentalmente la reguladora de las Haciendas locales, establecen respecto del principio de reserva de ley en tal materia». Igualmente, y ya refiriéndonos a otro «nivel» jurisprudencial, la Sentencia del Tribunal Superior de Justicia de la Comunidad Autónoma de Valencia, de fecha 25 de octubre de 1993, desestima la solicitud de planteamiento de una cuestión de inconstitucionalidad en relación con la ordenación de un precio público al entender que la regulación de la Ley de Haciendas locales es respetuosa con el principio de reserva de ley. En un sentido más rotundo aún se expresa la Sentencia del Tribunal Superior de Justicia de Extremadura, de fecha 22 de enero de 1996, al afirmar que la regulación de la Ley de Haciendas locales es constitucional puesto que «el Estado tiene,..., la potestad de dictar leyes, por contra a los municipios les está vedada esta posibilidad ya que el constituyente únicamente ha otorgado capacidad para dictar normas reglamentarias. La colaboración Ley y Reglamento en el ámbito local alcanza unos perfiles singulares, lo cual impide trasladar mecánicamente la doctrina del Tribunal Constitucional al caso que nos ocupa. El principio de reserva de ley no puede llegar a convertirse en un impedimento para que los Ayuntamientos intervengan de alguna forma en el diseño de su propia Hacienda, pues es voluntad del constituyente que los Ayuntamientos puedan producir normas en aspectos que les afecten sustancialmente».

4 Publicada en el $B O E$ de fecha 20 de enero de 2000, y que pone fin a los recursos de inconstitucionalidad n. ${ }^{\circ} 572 / 89,587 / 89$ y 591/89 (acumulados), promovidos respectivamente por el Consejo ejecutivo de la Generalidad de Cataluña, el Parlamento de Cataluña y D. Federico Trillo-Figueroa Martínez-Conde, comisionado por sesenta diputados; así como a las cuestiones de inconstitucionalidad, también acumuladas a las anteriores, números $2.679 / 96$ y 4.626/96, planteadas por la Sección Tercera de la Sala de lo Contencioso-administrativo del Tribunal Superior de Galicia, números $2.820 / 96$ y $4.646 / 96$, planteadas por la Sala de lo Contencioso-administrativo del Tribunal Superior de Justicia de Canarias con sede en Las Palmas, y número 745/97, planteada por la Sala de lo Contencioso-administrativo del Tribunal Superior de Justicia de Canarias con sede en Santa Cruz de Tenerife contra la Ley 39/1988, de 28 de diciembre.

5 Salvo el artículo 45.1 que ha sido declarado inconstitucional «en la medida en que resulte aplicable a los precios públicos exigibles por servicios $\mathrm{o}$ actividades de solicitud o recepción obligatoria, de carácter indispensable o prestados en régimen de monopolio de hecho o de derecho»; igualmente se declara en esta sentencia que los artículos 48.1 y 119.3 , para ser constitucionales, han de ser interpretados en el sentido que se expresa en los Fundamentos juridicos 18 y 35 de la citada sentencia. 
En el presente supuesto la Ley 25/1998, en un alarde de previsión legislativa ${ }^{6}$, regula de nuevo el régimen jurídico de las tasas y precios públicos locales antes que el Tribunal Constitucional hubiese dictado sentencia sobre la impugnación efectuada al contenido de la anterior Ley de Haciendas locales. Tal actuación supone, sin duda, una loable voluntad de adelantarse a la posible situación de inseguridad jurídica generada por una sentencia que pudiera declarar la inconstitucionalidad de alguno de los preceptos impugnados, situación que ha sido evitada al haberse dado una nueva redacción al contenido del único artículo, 45.1, declarado inconstitucional por esta Sentencia de fecha 16 de diciembre de 1999.

Y es que si algo se puede afirmar de la línea jurisprudencial construida hasta ahora por nuestro Tribunal Constitucional en esta materia es que ha resultado poco precisa y llena de ciertas contradicciones. Contradicciones que se detectan por cuanto a la par de efectuar proclamaciones de principios generales, "autonomía que, en lo que a las Corporaciones locales se refiere, posee también una proyección en el terreno tributario, pues éstos antes habrán de contar con tributos propios y sobre los mismos deberá la Ley reconocerlas una intervención en su establecimiento o en su exigencia, según previenen los artículos 140 y 133.2 de la misma Norma fundamental» ${ }^{7}$, se encuentran declaraciones precisas que restringen esta necesaria actuación normadora de las Entidades locales, al entender el principio constitucional de reserva de ley como argumento constitucional que impide a las Entidades locales «la

\footnotetext{
${ }^{6}$ Y ello dado que, como reconoce el propio legislador en su Exposición de Motivos, se trata de regular «una solución idéntica en el ámbito de las Haciendas locales pese a que la Sentencia del Tribunal Constitucional 185/1995, de 14 de diciembre, se circunscribe al contenido de la Ley 8/1989 en materia de precios públicos establecidos por la Administración estatal, sin pronunciamiento alguno respecto a la normativa vigente sobre precios públicos locales recogida en la Ley $39 / 1988$, de 28 de diciembre, reguladora de las Haciendas locales, en la medida en que, de un lado, unos y otros precios participan del mismo fundamento y, de otro lado, la nueva delimitación que del concepto de tasa hace la ley se inspira en los pronunciamientos de dicha sentencia, parece conveniente modificar también la regulación de las tasas y precios públicos para adaptarlos a la configuración que se establece en el ámbito estatal». Y es que si bien el legislador estatal no pretende mostrar, al menos expresamente, la idea de la posible inconstitucionalidad de la citada Ley de Haciendas locales, implícitamente viene a reconocer tal situación al declarar la necesidad de su modificación en lo que toca a la regulación «de las tasas y precios públicos locales para adaptarlos a la configuración que se establece en el ámbito estatal», lo que es lo mismo que decir, para adaptarlos a las declaraciones contenidas en la Sentencia del Tribunal Constitucional de $14 \mathrm{de} \mathrm{di-}$ ciembre de 1995.
}

${ }^{7}$ Sentencia de este Tribunal de fecha 17 de febrero de 1987, FJ IV. Aspecto éste que también nos recuerda la Sentencia de fecha 16 de diciembre de 1999, FJ XVIII. 
fijación «libre» de un elemento esencial en la definición de tales tributos» ${ }^{8}$.

Además, ha existido una falta de precisión en esta actuación del Tribunal Constitucional que ha impedido a los operadores normativos conocer, con cierto grado de previsibilidad jurídica al menos, cuál es el parámetro de constitucionalidad en esta materia para adecuar así su futura actuación. Pues al actuar como un «legislador negativo», pero sin precisar con un determinado grado de detalle el ámbito de actuación del principio de reserva de ley, no sólo se puede estar actuando por el Tribunal Constitucional sobre la configuración de otro principio constitucional, el principio de autonomía local, definido por el legislador estatal como consecuencia del ejercicio de una legítima opción política, sino que tal construcción «adolece del inconveniente de dejar indeterminado, por falta de cuantificación, cuáles son los límites concretos de libertad municipal en la fijación del tipo de gravamen que no vulneren el principio de legalidad tributaria» 9 .

Así las cosas, entendemos plausible la voluntad del legislador estatal, explicitada en esta Ley 25/1998, de permitir una alta participación de las Entidades locales en el establecimiento y ordenación de los «elementos esenciales» ${ }^{10}$ de las tasas locales; opinión favorable a esta ley que se refuerza cuando nos referimos a la importante participación que han tenido las Entidades locales en su elaboración, pudiendo ser considerada esta norma como un exponente del denominado «pacto local» ${ }^{11}$.

${ }^{8}$ Sentencia de este Tribunal de fecha 17 de febrero de 1987, FJ V, en cuanto se refiere al contenido del artículo 13.1 de la Ley 24/1983, de 21 de diciembre, que permitía a los municipios la fijación de los tipos impositivos de la contribución territorial rústica y urbana. $Y$ que vuelve a señalarse en la Sentencia de fecha 16 de diciembre de 1999, FJ XIX, al considerar que la técnica legislativa estatal que permite a los entes locales una absoluta libertad para determinar el quantum del tributo es contraria al principio de reserva de ley, como sucedía en el artículo 45.1 de la Ley de Haciendas Locales, en su redacción de 1988, al considerar la citada sentencia que la fijación de un límite mínimo por el legislador permite a las Entidades locales actuar con entera libertad; la solución del Tribunal Constitucional, para que se respete el principio de reserva de ley, es que el legislador fije «un límite máximo de la prestación de carácter público, o de los criterios para determinarlo».

9 Contenido del Voto particular emitido por el magistrado Sr. Díaz Eimil en la Sentencia citada de fecha 17 de febrero de 1987.

${ }^{10}$ Entendiendo por tales aquellos que se encuentran recogidos en el artículo 10 de la Ley General Tributaria, cuando señala que «Se regularán, en todo caso, por Ley: a) La determinación del hecho imponible, del sujeto pasivo, de la base, del tipo de gravamen, del devengo y de todos los demás elementos directamente determinantes de la cuantía de la deuda tributaria...»; precepto normativo que viene a constituir una plasmación del "principio de reserva de ley» en el orden tributario, Sentencia del Tribunal Supremo de fecha 9 de julio de 1997, o como ya antes habia puesto de manifiesto este Alto Tribunal en su Sentencia de fecha 19 de septiembre de 1988.

11 Dado que la regulación contenida en esta norma jurídica con relación a los precios públicos y tasas locales es consecuencia de los acuerdos alcanzados entre el Estado y la FEMP. Así, en el Bole- 


\section{CONCEPTO Y SIGNIFICADO DEL PRINCIPIO DE RESERVA DE LEY EN EL ÁMBITO TRIBUTARIO LOCAL}

\section{A. Referencia al origen del concepto de reserva de ley}

La construcción del principio de reserva de ley se ha concretado en la historia del Derecho público europeo en torno a una función garantista; esto es, si se aceptaba que la ley era la norma jurídica encargada de garantizar los derechos y bienes más apreciados por los ciudadanos ${ }^{12}$, para que este principio pudiese cumplir su máxima finalidad era necesario que las materias más importantes, según la conciencia de la sociedad, se excluyeran de la actividad normadora de cualquier órgano productor que no fuese la Asamblea legislativa ${ }^{13}$.

Y es así como MAYER ${ }^{14}$ definió expresamente en el Derecho alemán la reserva de ley, como aquel ámbito de actuación excluido de la iniciativa normadora del poder ejecutivo, y como ha venido siendo tradicionalmente considerada.

De esta forma, y en su origen histórico medieval ${ }^{15}$, las reservas de ley tenían por finalidad asegurar que la actuación de la Administración real

tin Oficial de las Cortes Generales, Congreso de los Diputados, Serie Proyectos de Ley, n. ${ }^{\circ} 91-6$, de fecha 6 de marzo de 1998, podemos advertir que la redacción del actual artículo 66 fue consecuencia de la introducción de las enmiendas n. ${ }^{\circ}$ 67, del Grupo Popular, y 82, del Grupo Catalán, al Proyecto de Ley presentado por el Gobierno; y en la justificación ofrecida en la enmienda n. ${ }^{\circ} 67$ se puede leer literalmente lo siguiente: «Se trata de un conjunto de mejoras que afectan a casi todos los artículos de la Ley 39/1983, de 28 de diciembre, reguladora de las Haciendas locales... Estas mejoras son el resultado de los estudios y reuniones celebradas entre los servicios técnicos de la Administración del Estado y la Federación Española de Municipios y Provincias (FEMP)».

12 L. MARTín-Retortillo señala cómo el nacimiento de este principio jurídico fue una de las grandes preocupaciones de los juristas en la configuración del Estado de Derecho liberal, «La doctrina de las materias reservadas a la Ley y la reciente jurisprudencia del Tribunal Supremo", $R A P \mathrm{n} .^{\circ} 39$, 1962, p. 291.

13 Así, y como nos recuerda A. Gallego Anabitarte, en Ley y reglamento en el Derecho Público Occidental. IEA, Madrid, 1971, p. 275, las Constituciones de varios Estados alemanes, fundamentalmente del Sudoeste (Badem, Wutttenberg, etc.), establecían la necesidad de la aprobación por las Dietas de leyes generales que afectasen a la libertad y a la propiedad. $Y$ es que en este pais, como señala R. GARCIA MACHO, en Reserva de Ley y potestad reglamentaria, Ariel Derecho, Barcelona, 1988, p. 29, la construcción de este principio se debe a una necesidad de la burguesia por aumentar su ámbito de actuación en materia normativa.

14 O. MAYer, Le Droit Administratif Allemand, Girard \& Briève, Paris, 1903, p. 92, califica estos ámbitos materiales como "certains objets particulièrement importants», y los determina como aquellos que afectasen a la imposición de cargas o regulasen la libertad y la propiedad.

15 Pues este principio ya se encontraba en los textos legales de la Edad Media; en este sentido, y en referencia a nuestro Derecho, G. ArIÑo OrTIZ, «Derecho del Rey, Derechos del Pueblo (Apuntes 
sólo pudiera incidir sobre ciertos bienes de los individuos con la previa autorización de éstos manifestada mediante una ley ${ }^{16}$.

Esta justificación tradicional del principio de reserva de ley, como garantía de los ciudadanos de que la regulación sobre las materias que afectasen a los aspectos más trascendentales fuese realizada por sus representantes en el poder legislativo, ha sido aceptada por nuestro Tribunal Constitucional, Sentencias de 24 de julio de 1984 , recurso n. $^{\circ} 80 / 83$, y 17 de febrero de 1987 , recurso $n .^{\circ} 665 / 84$, y también aparece recogida por un importante sector de la doctrina de nuestro país ${ }^{17}$.

En este sentido, y ya en una vertiente tributaria, nuestro Tribunal Constitucional viene entendiendo que «el principio de legalidad en materia tributaria responde en esencia a la vieja idea, cuyo origen se remonta a la Edad Media, de garantizar que las prestaciones que los particulares

para la configuración histórica del principio de materias reservadas), Actas de II Symposium de Historia de la Administración, Madrid, 1971, señala que «nuestros textos doctrinales y legales afirmarían una y otra vez la doctrina del poder como pacto o contrato con el Reino, según el cual el Rey carece de poderes de disposición sobre el Reino en una serie de ámbitos o materias que el pueblo se ha reservado», p. 90, por lo que la expresión tradicional en nuestra legislación «derecho del rey, derechos del pueblo» no encerraría sino «lo que actualmente se llama principio de reserva de ley», p. 43.

16 I. DE OTTO, Derecho Constitucional. Sistema de Fuentes, Barcelona, 1991, p. 152.

17 Así E. Garcta de Enterría y T. R. Fernandez-Rodríguez, Curso de Derecho Administrativo, tomo I, Madrid, 1997, pp. 239 y ss., señalan que el principio de reserva de ley en su sentido tradicional tiene una plasmación en nuestro texto constitucional que puede destacarse del contenido «del artículo 53.1, que tiene un claro alcance general y en el que hay que situar necesariamente la regla fundamental sobre el tema de las materias reservadas en nuestro sistema». Dado que «finalmente, si quiere agotarse el paralelismo de nuestro sistema vigente con la formulación tradicional del principio de reserva de ley, habrá que notar que no sólo la libertad, también la propiedad constituye una materia reservada a la ley según expresamente dispone el artículo 33.2». I. DE OTTO, Derecho..., cit., pp. 152 y 153 , señala también como fundamento de este principio el de que «la garantía de la libertad, su protección frente a toda restricción que no emane precisamente de los representantes del pueblo, sólo puede asegurarse por eso imponiendo a éstos la obligación de adoptar por sí mismos las normas que la imponen». Concepción a la que se opone M. REBOLlo Pug, «Juridicidad, legalidad y reserva de ley como límites a la potestad reglamentaria del Gobierno", $R A P, \mathrm{n} .{ }^{\circ} 125,1991$, p. 127, por entender que en nuestro texto constitucional no se puede hacer coincidir el ámbito de la reserva de ley «con el de las limitaciones a la libertad y a la propiedad», dejando este autor el fundamento jurídico de este principio únicamente «en el Derecho constitucional, de manera que para determinar su ámbito no existe otra vía que deducirlo de las previsiones constitucionales». Apuntando R. GARCí MACHo, cit., p. 114, que el fundamento de este principio era el de asegurar que la regulación de ciertas materias se haga mediante el procedimiento legislativo, es decir, a través de una discusión pública con participación de la oposición y del conocimiento accesible a los ciudadanos. Y es que para este otro sector de nuestra doctrina el principio de reserva de ley no sería sino una «técnica de distribución de potestades normativas", J. A. Santamaria Pastor, Fundamentos de Derecho Administrativo I, Areces, Madrid 1991, p. 755, como ya pusiera de manifiesto L. MARTIN-RETORTILLO, «La doctrina de las materias reservadas a la Ley y la reciente jurisprudencia del Tribunal Supremo», cit., p. 289. 
satisfacen a los Entes públicos sean previamente consentidas por sus representantes; la reserva de ley se configura como una garantia de autoimposición de la comunidad sobre sí misma y, en última instancia, como una garantia de la libertad patrimonial y personal del ciudadano. En el Estado social y democrático de Derecho la reserva cumple sin duda otras funciones, pero la finalidad última (...) continúa siendo la de asegurar que cuando un ente público impone coactivamente una prestación patrimonial a los ciudadanos, cuente para ello con la voluntaria aceptación de sus representantes" ${ }^{18}$.

\section{B. Corrección del alcance y significado tradicional de este principio constitucional en el ámbito tributario local}

Se puede apuntar que esta función garantista del principio de reserva de ley podría verse también satisfecha con la actuación de los órganos normadores de las Entidades Locales, Pleno de los Ayuntamientos y Diputaciones, pues todos ellos son elegidos democráticamente ${ }^{19}$; y ello hasta el extremo de que en algunas entidades locales serían los propios vecinos quienes por sí y directamente gestionasen sus intereses ${ }^{20}$.

Por ello el significado y aplicación del principio de reserva de ley tiene que ser corregido cuando actúa en materias que afectan a las Entidades locales, dado que no sólo se puede ver cumplida en este ámbito su tradicional función, en el sentido de garantizarse una participación de los ciudadanos en la actividad normativa ${ }^{21}$, sino que tal corrección resulta im-

\footnotetext{
18 Sentencia del Tribunal Constitucional de fecha 14 de diciembre de 1995, FJ III. Y ello hasta el punto de hacer coincidir el ámbito de actuación del principio de reserva de ley con la nota de la "coactividad»; así, en esta sentencia se señala que "cuando la obligación que lleva aparejada el pago de la prestación es asumida libre y voluntariamente por el ciudadano, la intervención de sus representantes resulta innecesaria, puesto que la garantía de la autoimposición y, en definitiva, de su libertad patrimonial y personal queda plenamente satisfecha».
}

19 Opinión que también comparte J. J. Ferreiro Lapatza, «La Hacienda local...», cit., p. 49, cuando señala que «la ley deja de monopolizar, en el caso de las Ordenanzas, el papel de garante de la representación popular frente al ejecutivo. De garantía de la autoimposición para pasar a compartir, al menos, este papel con la Ordenanza».

${ }^{20} \mathrm{El}$ artículo 29, apartado tercero, de la Ley reguladora de las Bases del Régimen Local de 1985, establece que en los Concejos Abiertos «el gobierno y la administración corresponden a un Alcalde y una Asamblea vecinal de la que forman parte todos los electores». Y de esta forma el Tribunal Constitucional ha declarado, respecto de este tipo de Entidades locales, que constituyen un supuesto de forma de democracia directa «en los que la toma de decisiones políticas se realiza mediante un llamamiento directo al titular de la soberanía", Sentencia de fecha 17 de julio de 1995, FJ III.

${ }^{21}$ Que se encuentra garantizado en el procedimiento para la elaboración y aprobación de las Ordenanzas fiscales, artículo 49 de la Ley de Bases de Régimen local y 16 y ss. de la Ley de Haciendas 
prescindible para que se produzca también el efectivo cumplimiento del principio constitucional de autonomía local para la gestión de sus intereses respectivos 22 .

En este ámbito se produce la confluencia de dos principios constitucionales que han de ser «integrados»: la reserva de ley como instrumento de garantía de los derechos de los ciudadanos, por una parte, artículo 31.3 $\mathrm{CE}$; y, por otra, la autonomía local que garantiza la participación de las Entidades locales en la gestión de sus intereses respectivos, artículo 137 CE.

Nuestro Tribunal Constitucional ya ha tenido ocasión de poner de manifiesto esta necesidad de integración de estos dos principios constitucionales, en su Sentencia de fecha 17 de febrero de 1987, cuando ha sancionado que "el sentido que hay que reconocer en la reserva introducida por el artículo 31.3 de la Constitución no puede entenderse, sin embargo, desligado de las condiciones propias al sistema de autonomías territoriales que la Constitución consagra (art. 137), y especificamente -en el presente proceso- de la garantía constitucional de la autonomía de los municipios (art. 140)» ${ }^{23}$.

locales, tanto en la redacción originaria como en la establecida por la Ley 50/1998, de 30 de diciembre, de Medidas Fiscales, Administrativas y del Orden Social, al establecer los trámites de audiencia al interesado e información pública, sobre todo de este último que se impone con carácter obligatorio, y residenciar la competencia para la aprobación de estas normas en el Pleno de la Corporación, [art. 22.2, d) de la citada Ley de Bases]; siendo estos requisitos procedimentales los que aspiran a garantizar en el orden tributario local el cumplimiento del principio de reserva de ley, según la Sentencia del Tribunal Supremo de fecha 22 de enero de 1996, cit. Y ello hasta el punto de consagrarse, en la referida Sentencia del Tribunal Constitucional de 16 de diciembre de 1999, FJ XVIII, la exigencia de que el órgano local que apruebe la ordenanza tributaria ha de ser necesariamente el Pleno, dado que éste al ser «formado a partir de la elección por sufragio de los vecinos de la Corporación local, cumple con las exigencias del fundamento último de la reserva de ley tributaria, a saber, que cuando un ente público impone coactivamente una prestación patrimonial a los ciudadanos cuenta para ello con la voluntaria aceptación de sus representantes», por lo que no cabe delegación de esa competencia ni en el Alcalde ni en la Comisión de Gobierno (y ello pese a la redacción dada por la Ley 11/1999, de 21 de abril, del artículo 22.4 de la Ley de Bases, que ha de ser interpretado en el sentido que nos ordena el Tribunal Constitucional).

22 En similares términos se expresa I. LaSAGabaster Herrarte, Las relaciones de sujeción especial, Madrid, 1994, pp. 283 y 284, cuando considera que la reserva de ley no puede ser interpretada «haciendo abstracción de la estructura política del Estado», dado que ésta «no puede ser interpretada de tal forma que las Corporaciones locales vean impedida su actuación sobre un determinado haz de competencias».

${ }^{23}$ FJ IV. De esta forma A. EmBID Irujo, «Potestad reglamentaria», RVAP n. ${ }^{\circ} 29$, enero-abril 1991, p. 105, opina que «la cláusula de la garantía constitucional de la autonomía sería, precisamente, la causa de esa relación singular que permitiria un mayor grado de "independencia", de "no sujeción" a la Ley de estos Reglamentos". 
De lo señalado se deduce la existencia de una interacción de dos principios jurídicos históricamente sucesivos: el de la participación de los ciudadanos en la elaboración de las leyes a través de las Asambleas Legislativas - reserva de ley-, propio del Estado liberal del siglo XIX y en el cual existía una contraposición del poder público y de la sociedad, de forma que el Estado sólo podía regular las materias que afectasen más esencialmente a los bienes y derechos de aquélla previa aceptación por sus representantes en las Dietas ${ }^{24}$; y el de la distribución de las funciones entre entes públicos de base territorial distintos del Estado, principio jurídico fortalecido a mediados y finales del siglo $\mathrm{XX}$.

La solución que desde aquí se propugna, para aunar y armonizar ambos principios, es declarar la posibilidad de las Entidades locales de «coparticipar» ${ }^{25}$ en la regulación normativa de las materias reservadas tradicionalmente a las leyes, siempre que en éstas no se encuentre ausente el interés respectivo de aquéllas, ni se violente el interés general o autonómico, con la consiguiente corrección del tradicional alcance de la reserva legal en las materias afectadas por la existencia de un interés local ${ }^{26}$.

24 Es ésta la tesis que sostiene nuestro Tribunal Constitucional; así, en su Sentencia de fecha 17 de febrero de 1987, FJ IV, establece que "como ocurre con otras reservas de ley presentes en la Constitución, el sentido de la aquí establecida no es otro que el de asegurar que la regulación de determinado ámbito vital de las personas dependa exclusivamente de la voluntad de sus representantes»; configuración que vuelve a reiterarse en posteriores Sentencias, 7 de abril de 1987, 29 de septiembre de 1988, y 20 de octubre de 1990, cuando señala que la finalidad de la reserva de ley es la de «asegurar que en determinados ámbitos de transcendencia en las personas o en la sociedad dependan exclusivamente de la voluntad de sus representantes»

${ }^{25}$ Y ello en cierta conexión temática (dada la finalidad común perseguida de integrar en la regulación de una misma materia diversas voluntades e intereses), con la construcción teórica suscitada en Alemania sobre la necesidad de modificar el contenido del concepto de «reserva de ley» para adecuarlo a las actuaciones propias de la Administración prestacional que, según L. PAREJO ALFONSO, Crisis y Renovación en el Derecho Público, Madrid, 1991, pp. 56 y ss., se sitúa en tomo a la teoría de la esencialidad. Esta teoria parte del aserto de que el fin de la división de poderes y de la distribución y asignación de funciones distintas a diferentes órganos no es otro, en la Constitución, que el de asegurar que las decisiones estatales se adoptan lo más acertadamente posible, es decir, por los órganos que reúnen mejores condiciones para ello, por lo que la diferencia más importante ente el Parlamento y el Ejecutivo no es sino su funcionamiento en el procedimiento de toma de decisiones. Por ello el procedimiento legislativo «es especialmente complejo y está dirigido a permitir una plural intervención y un amplio debate (...), que hacen de él un locus especialmente idóneo para la realización de dichos valores y, por tanto, especialmente dotado para producir decisiones acertadas en el sentido pretendido constitucionalmente». Valores que no solamente descansan sobre el contenido material o sustancial de la decisión, sino también respecto de: la armonía interna de las decisiones, participación del pueblo en éstas, claridad sobre lo que sea justo o no de Derecho y, también, sobre la integración politica. Además, y según continúa señalando Parejo Alfonso, H. H. von ARNim apunta la muy interesante posibilidad de aplicar esta teoria de la esencialidad también a las relaciones entre los distintos poderes públicos territoriales, y, dentro de éstos, entre los «órganos equivalentes» a los del legislativo y ejecutivo del Estado.

${ }^{26}$ Según también concluye I. LASAGABASTER HerRARTE, Las relaciones..., cit., p. 248, cuando señala que esta minoración «puede dar lugar a la emanación de Ordenanzas locales que tengan los caracteres 
Para ello será imprescindible poner en relación y articular los principios básicos organizativos, la autonomía y el interés local, con el resto de preceptos constitucionales; pues de lo contrario se aceptaría una exclusión de la actuación normadora de las Entidades locales en las materias reservadas a la ley, lo que sería contradictorio con la Constitución por cuanto ella reconoce y garantiza su participación en la gestión de sus intereses.

De esta forma, y como sucede en otros muchos problemas del Derecho público en los que confluyen varios principios constitucionales igualmente protegibles, la solución que se propugne deberá integrar todos ellos en un sentido armonizador del orden constitucional ${ }^{27}$.

La situación pues, como ya se señalaba, se traslada de una actuación normativa única, la de la Asamblea legislativa del Estado como único órgano legítimamente representativo de la voluntad de los ciudadanos, a otra realidad constitucional integrada por una pluralidad de órganos normadores también representativos de una voluntad de ciudadanos, pero de ámbito territorial distinto, $\mathrm{y}$, por ende, con una cualidad diferente, lo que evidencia, bien a las claras, la necesidad de una reinterpretación, bajo estos parámetros, del principio de reserva de ley, que se ve corregido en su tradicional alcance ${ }^{28}$.

\begin{abstract}
de las normas reglamentarias autónomas, independientes o ejecutivas», es decir, la capacidad de realizar normas «dictadas en materias reservadas a esta fuente normativa» y en un ámbito "vvedado al legislador ordinario». En materia tributaria local A. MENÉNDEZ MORENO, «El poder tributario de las Corporaciones locales», cit., p. 2112, ha señalado la posibilidad a las Entidades locales de que puedan regular «las exenciones, el contribuyente, el sustituto y el retenedor, el repercutido, el responsable y la base imponible», e incluso, respecto de los tributos destinados a su financiación, el establecimiento de gravámenes (aunque esta posibilidad haya sido declarada, con posterioridad a la redacción de este trabajo, inconstitucional por la Sentencia del Tribunal Constitucional de fecha 19 de diciembre de 1985, al considerar que es al legislador estatal «a quien incumbe, en virtud del principio de reserva de ley»). Y es que, como señala la Sentencia del Tribunal Constitucional de 16 de diciembre de 1999, FJ XVIII, «la reserva de ley tributaria en el ámbito local también encuentra su fundamento en la preservación de la unidad del ordenamiento y de una básica igualdad de posición de los contribuyentes», que se erigen asi en dos intereses generales que ha de alcanzar y garantizar este principio constitucional a través de la actuación legisladora del Estado (corrigiendo así el tradicional y univoco fundamento del principio de reserva de ley antes reseñado).

${ }^{27}$ So pena de aceptar que en la Constitución existen contradicciones irreductibles que, pugnando con el principio lógico-juridico de integridad del texto constitucional, significarían la inutilidad de una norma jurídica superior en nuestro ordenamiento jurídico, a lo que se opone de manera tajante el propio Tribunal Constitucional, en Sentencia ya citada de 17 de febrero de 1987, FJ IV, al señalar que «la integridad de la Constitución y del orden por ella introducido en nuestro Derecho quedaría ciertamente menoscabada si cualquiera de sus prescripciones quisiera (...) sobreponerse a lo dispuesto por la propia Constitución en otro de sus preceptos»".
\end{abstract}

${ }^{28}$ Lo que ha sido denominado por nuestro Tribunal Constitucional, siguiendo aquí a un sector de la doctrina española, como una «reserva relativa» que «cuando se trata de ordenar por ley los tributos 


\section{DETERMTNACIÓN DEL ÁMBITO DE DISCUSIÓN: SOBRE LA UBICACIÓN Y EFECTOS DE LA LEY 25/1998, DE 13 DE JULIO, EN RELACIÓN AL PRINCIPIO DE RESERVA DE LEY}

La finalidad básica de esta Ley, en lo que atañe a la materia tributaria local, se centra en intentar adecuar la regulación contenida en la Ley de Haciendas locales, de 28 de diciembre de 1988, sobre precios públicos y tasas, a los principios contenidos en la Sentencia del Tribunal Constitucional de fecha 14 de diciembre de $1995^{29}$, básicamente a través de ofrecer una nueva regulación de los tipos tributarios que se integran en el concepto de tasas, y que antes eran considerados como precios públicos (utilización privativa o aprovechamiento especial del dominio público local o la prestación de un servicio público o la realización de actividades administrativas de competencia local y exista coactividad o no sustituibilidad por el sector privado, en este último caso) ${ }^{30}$.

En este sentido, esta ley efectúa una regulación del régimen jurídico de las tasas locales, instrumento tributario afecto al principio de reserva de ley por constituir una "prestación patrimonial de Derecho público» ${ }^{31}$ (art. 31.3 de la Constitución), cuyo contenido es precisamente el objeto de este trabajo. Y la regulación normativa de este instrumento tributario es realizada de tal modo que se constituye en todo un exponente legislativo de la articulación de la normativa estatal y local en un ámbito sectorial de materias compartidas ${ }^{32}$; de esta forma, podemos afirmar que allí don-

locales, esta reserva ve confirmada constitucionalmente su parcialidad, esto es, la restricción de su ámbito", Sentencia de fecha 17 de febrero de 1987, ya citada.

${ }^{29}$ Y que parece haber conseguido su objetivo a la vista de la Sentencia del Tribunal Constitucional de 16 de diciembre de 1999, como ahora veremos.

${ }^{30}$ Artículos 20 y 41 de la Ley de Haciendas locales en la nueva redacción efectuada por la Ley 25/1998, de 13 de julio, siguiendo la interpretación efectuada por la Sentencia del Tribunal Constitucional de fecha 14 de diciembre de 1995, ya citada.

${ }^{31} \mathrm{Y}$ es que esta Ley no hace sino trasvasar al orden legislativo los contenidos jurídicos alcanzados por nuestro Tribunal Constitucional en su Sentencia de fecha 14 de diciembre de 1995, cit., FJ III y IV fundamentalmente, en la que, sobre la característica de la "coactividad» que «es la nota distintiva fundamental del concepto de prestación patrimonial de carácter público", se estudia cada uno de los presupuestos de hecho que ahora integran el concepto de las tasas y alcanza la conclusión que es un supuesto de prestación patrimonial de carácter público que «en cuanto tal queda sometida a la reserva de ley", FJ IV.

${ }^{32} \mathrm{Y}$ aunque en términos generales la técnica normativa contenida no sea distinta a la utilizada por el legislador en la Ley de Haciendas locales de 1988, el texto de la nueva ley supone tanto una consagración de la capacidad normativa de las Entidades locales con un ámbito de actuación normativo importante, como la consolidación del papel a desempeñar por las Ordenanzas locales en la regula- 
de esta ley se remite a la posterior intervención normativa para la regulación de los «elementos esenciales» de las tasas estatales, o para su «establecimiento», lo que «deberá realizarse con arreglo a Ley 33", en el ámbito de las tasas locales esta posterior actuación normativa se efectuará por las Entidades locales a través de normas jurídicas que no tienen otra naturaleza jurídica que la reglamentaria.

En otras palabras, y haciendo expresa la conclusión jurídica que queremos alcanzar o refutar en este trabajo, el reglamento local juega en el ámbito de la regulación normativa de las tasas locales similar papel al que la ley estatal desempeña en el ámbito de la regulación de las tasas estatales.

Intentando acreditar esta afirmación podemos decir:

\section{A. El ámbito de actuación de la reserva de ley tributaria en esta norma}

\section{1. ${ }^{\circ}$ Sobre el establecimiento de los diversos tipos de tasas locales}

La Ley 25/1998, de 13 de julio, conforma uno de los tipos de las prestaciones patrimoniales de Derecho público - las tasas - definiéndolas como aquellas prestaciones patrimoniales que establezcan las Entidades locales, «en los términos previstos en esta Ley» ${ }^{34}$, por la utilización privativa o el aprovechamiento especial del dominio público local, o por la prestación de un servicio público, o la realización de una actividad administrativa en régimen de Derecho público, $\mathrm{o}$, en definitiva, por aquella prestación de una actividad administrativa caracterizada por la coactividad «en el establecimiento unilateral de la obligación de pago por parte del poder público sin el concurso de la voluntad del sujeto llamado a satisfacerla» ${ }^{35}$; pero habilita, en cualquier caso, a las Entidades locales

ción del ámbito tributario local, distinto y cualitativamente superior al que desempeñan los reglamentos estatales y autonómicos con relación a sus leyes respectivas.

${ }^{33}$ Contenido de la nueva redacción del artículo 10 , apartado $1 .^{\circ}$, de la Ley de Tasas y Precios Públi$\cos$, que significa el establecimiento de una reserva de ley expresa en esta materia, quedando la intervención reglamentaria restringida al mero desarrollo o concreción de aspectos previamente regulados por ley («cuando se autorice por Ley, con subordinación a los criterios o elementos de cuantificación que determine la misma, se podrán concretar mediante norma reglamentaria las cuantías exigibles por cada tasan, apartado $3 .^{\circ}$, de este art. 10).

${ }^{34}$ Así se establece literalmente en el apartado primero del artículo 20 de la Ley de Haciendas locales, en la nueva redacción efectuada por la Ley 25/1998.

35 Utilizando literalmente las expresiones recogidas en la Sentencia del Tribunal Constitucional de fecha 14 de diciembre de 1995, cit., FJ III. 
para que establezcan aquellas tasas que consideren convenientes, siempre dentro de esta previa determinación legislativa.

Y ello hasta el punto que cuando en los apartados $3 .^{\circ}$ y $4 .^{\circ}$, en la nueva redacción del artículo 20 que efectúa esta Ley, se enumeran las diversas clases de tasas que pueden «establecer» las Entidades locales, ello se realiza a efectos meramente ejemplificativos ("Conforme a lo previsto en el apartado 1 anterior, las Entidades locales podrán establecer tasas por cualquier supuesto de utilización privativa o aprovechamiento especial del dominio público, y en particular por los siguientes... Conforme a lo previsto en el apartado 1 anterior, las Entidades locales podrán establecer tasas por cualquier supuesto de prestación de servicios o de realización de actividades administrativas de competencia local, y en particular por los siguientes») ${ }^{36}$.

Por tanto, el legislador estatal deja en libertad a las Entidades locales para que éstas decidan establecer o no las tasas en los supuestos de hecho enumerados en estos preceptos, o para concretar otros supuestos de hechos en los que, existiendo la nota característica de la «coactividad», puedan establecer tasas ${ }^{37}$.

Y esta actuación, obviamente, sólo podrá ser realizada por las Entidades locales por medio de normas jurídicas con rango reglamentario, Ordenanzas fiscales ${ }^{38}$, que deberán ser aprobadas siguiendo el procedi-

${ }^{36}$ En este sentido se expresa también la Justificación de la Enmienda n. ${ }^{\circ} 67$ presentada por el Grupo Popular al Proyecto de esta Ley, BOCD, n..$^{\circ}$ 1-6, cit., p. 55, al señalar que «los apartados 3 y 4 del artículo 20 realizan una enumeración de los supuestos en que las Entidades locales pueden establecer tasas por la utilización privativa o el aprovechamiento especial del dominio público local, o por la prestación de un servicio o la realización de una actividad administrativa, respectivamente. Dichas enumeraciones no son limitativas, sino simplemente ilustrativas, dejándose abierta la posibilidad de establecer tasas en supuestos distintos de los enumerados siempre que se den los presupuestos que configuran su hecho imponible».

${ }^{37}$ Imponiendo sólo una restricción negativa, la contenida en el artículo 21 de la Ley de Haciendas Locales, al impedir que las Entidades locales puedan exigir tasas por los uservicios siguientes: a) Abastecimiento de aguas en fuentes públicas. b) Alumbrado de vías públicas. c) Vigilancia pública en general. d) Protección civil. e) Limpieza de la vía pública. f) Enseñanza en los niveles de educación obligatoria». Lo cual viene a constituir una condición básica de carácter negativo, que no pueden contradecir las Entidades locales, para alcanzar un «común denominador» en la regulación normativa de las tasas locales en la totalidad del Estado que nunca podrán gravar estos servicios públicos locales (integrados en el artículo 25, apartado 2..$^{\circ}$, de la Ley reguladora de las Bases del Régimen Local, de 2 de abril de 1985, y que ahora son calificados por el Estado como servicios públicos gratuitos).

${ }^{38}$ De esta forma, el artículo 15.1 de la Ley de Haciendas locales establece que «las Entidades locales deberán acordar la imposición y supresión de sus tributos propios y aprobar las correspondientes Ordenanzas fiscales reguladoras de los mismos»; contenido normativo que desarrolla el artículo 106.2 de la Ley reguladora de las Bases del Régimen Local, Ley 7/1985, de 2 de abril, cuando es- 
miento legalmente establecido en los artículos 15 a 19 de la Ley de Haciendas locales, procedimiento de elaboración de estas normas jurídicas que es de una enorme importancia puesto que garantiza la participación de los ciudadanos.

Pues bien, esta solución legislativa parece plenamente acorde con el texto constitucional por cuanto queda garantizado el cumplimiento del principio de reserva de ley al delimitarse por el legislador estatal «el presupuesto de hecho de los precios públicos en términos suficientemente precisos como para circunscribir adecuadamente la decisión de los municipios» ${ }^{39}$.

\section{2. ${ }^{\circ}$ Sobre el establecimiento del hecho imponible}

Si la configuración y existencia de la tasa local corresponde a la Entidad local, sin más limitaciones que referirse a una situación de aprovechamiento especial del dominio público local o a su utilización privativa o a la prestación de un servicio público o la realización de una actividad administrativa de competencia local, resultará obvio que la determinación del hecho imponible de estas tasas corresponda a la propia Entidad local, que deberá efectuarlo a través de una norma reglamentaria.

De esta forma, cuando el artículo 20 de la Ley de Haciendas locales configura y define lo que ha de entenderse por tasas, no está determinando tanto cuál es su hecho imponible, sino que está estableciendo los elementos básicos que permitan conocer los presupuestos de hecho que puedan constituir los diversos tipos de tasas ${ }^{40}$. Así se pretende alcanzar una

tablece que «la potestad reglamentaria de las Entidades locales en materia tributaria se ejercerá a través de ordenanzas fiscales reguladoras de sus tributos propios y de ordenanzas generales de gestión, recaudación e inspección».

\footnotetext{
39 Sentencia de fecha 16 de diciembre de 1999, FJ XVIII, y referida al artículo 41 de la Ley de Haciendas Locales en su redacción de 1988, y que mutandis mutandi es extrapolable a la redacción del artículo 20 de esta Ley en su versión dada por la Ley 25/1998.

${ }^{40}$ Esta interpretación que defendemos queda reforzada con la nueva redacción otorgada al artículo 20 de la Ley de Haciendas locales; si antes este articulo quedaba encabezado bajo la rúbrica «Subsección 1. ${ }^{\mathrm{a}}$ - Hecho imponible», y en su apartado primero se decía, «Constituye el hecho imponible de las tasas...», en la actual redacción de este precepto no sólo desaparece el citado encabezamiento, sino que ha desaparecido cualquier referencia a la expresión «hecho imponible». Y es que, como se señala en la Justificación de la Enmienda n. ${ }^{\circ} 67$ del Grupo Popular, cit., p. 55, en relación con este artículo 20.1, «La modificación propuesta trata, en primer lugar, de flexibilizar el concepto de tasa, manteniendo su esencia y adaptándolo a las especialidades que concurren en la Hacienda local, de forma tal, que necesariamente deben revestir la forma de tasas aquellas prestaciones patrimoniales en las que concurren las circunstancias que de acuerdo con la Sentencia del Tribunal
} 
regulación normativa de los supuestos de hecho que, en caso de ser gravados por las Entidades locales, deberán serlo a través de las tasas - garantizando así el principio de reserva de ley.

\section{$3^{\circ}{ }^{\circ}$ Sobre la determinación de la cuantía de las tasas}

En este punto el legislador efectúa una doble regulación jurídica:

a) En relación con las tasas referidas al aprovechamiento o utilización privativa del dominio público local se establece, artículo 24 de la Ley de Haciendas locales, un limite determinado, el importe de la tasa «se fijará tomando como referencia el valor que tendría en el mercado la utilidad derivada de dicha utilización o aprovechamiento, si los bienes afectados no fuesen de dominio público» ${ }^{41}$.

b) En relación con las tasas referidas a la prestación de un servicio público o la realización de una actividad de competencia local, el legislador estatal establece el siguiente límite, «el importe de la tasa... no podrá exceder, en su conjunto, del coste real o previsible del servicio o actividad de que se trate o, en su defecto, del valor de la prestación recibida».

Solución legislativa, para ambos supuestos, que también parece plenamente constitucional dado el contenido de la Sentencia del Tribunal Constitucional de fecha 16 de diciembre de 1999, que considera que el cumplimiento del principio de reserva de ley obliga a «la determinación en la Ley de un límite máximo de la prestación de carácter público, o de los criterios para determinarlo» ${ }^{42}$.

Pero más allá de estas dos limitaciones que, por otra parte, coinciden casi absolutamente con las establecidas para las tasas estatales ${ }^{43}$, las

Constitucional 185/1995, de 14 de diciembre, así lo exigen, pero que a su vez no imposibilita el que otras prestaciones de servicios o realización de actividades pueda revestir la forma de esta categoría tributaria».

41 Y llega a señalarse en el párrafo tercero de este precepto que «Cuando se trate de tasas por utilización privativa o aprovechamientos especiales constituidos en el suelo, subsuelo o vuelo de las vías públicas municipales, en favor de empresas explotadoras de servicios de suministros que afecten a la generalidad o a una parte importante del vecindario, el importe de aquéllas consistirá, en todo caso y sin excepción alguna, en el 1,5 por 100 de los ingresos brutos procedentes de la facturación que obtengan anualmente en cada término municipal las referidas empresas».

${ }^{42}$ FJ XVIII de esta sentencia.

${ }^{43}$ Para comprobar este extremo no es necesario sino comparar el contenido del artículo 19, apartados $1 .^{\circ}$ y $2 .^{\circ}$, de la Ley de Tasas y Precios Públicos, en la nueva redacción efectuada por esta Ley 
Entidades locales tienen libertad para establecer la cuantía de la tasa - cuota tributaria-, a través de sus propias normas reglamentarias, Ordenanzas fiscales. Esta situación normativa contrasta con las tasas estatales; para éstas la determinación de su cuantía debe ser efectuada a través de una ley formal (tal y como se previene en la Disposición Final primera de la Ley ${ }^{44}$ ), y ello hasta el punto que la Disposición Final segunda de esta Ley establece que la modificación de su cuantía deberá efectuarse a través de «las Leyes de Presupuestos Generales del Estado».

Resulta particularmente ejemplificativo, a estos efectos, que la cuantía de la «tasa por publicación de anuncios en el BOE» se encuentra regulada por una Ley, de fecha 30 de diciembre de 1996 (y así lo recoge expresamente el art. 12 de esta Ley 25/1998), y su variación deberá efectuarse de forma que «sólo podrán modificarse mediante Ley el número e identidad de los elementos y criterios de cuantificación en base a los cuales se determinan las cuotas y tipos exigibles" (art. 17). Por el contrario, las Entidades locales titulares de los Boletines Oficiales de la Provincia pueden determinar a través de sus normas reglamentarias las cuantías de las tasas de los anuncios insertos en éstos, «Las Diputaciones Provinciales seguirán editando y publicando el «Boletín Oficial» de la provincia, pudiendo a tal efecto establecer y exigir tasa y precios por la inserción de anuncios y edictos y la suscripción y venta de ejemplares» (Disposición Adicional 5. de la Ley 25/1998).

\section{4. ${ }^{\circ}$ Sobre el pretendido Derecho transitorio de las tasas locales}

La Disposición Transitoria $2 .^{a}$ de esta norma trata de regular el delicado tema de la situación jurídica de la normativa dictada por las Entidades locales y reguladora de las ahora configuradas como tasas locales. El legislador estatal adopta el criterio de otorgar un plazo de tiempo, hasta el día 1 de abril de $1999{ }^{45}$, para que las Entidades locales aprueben y publi-

$25 / 1998$, con el señalado para las tasas locales en la nueva redacción dada al artículo 20, apartados $1 .^{\circ}$ y $2 .^{\circ}$, de la Ley de Haciendas locales.

44 En este precepto se recoge una suerte de «legalización formal» de las tasas estatales, incluida pues su cuantia, y ello determinando que las tasas estatales vigentes serán aquellas que viniesen ya establecidas por cada una de las normas de su creación, que, de tener naturaleza reglamentaria (vid. tasas de los juegos de suerte, envite o azar, tasas del Instituto Nacional de Estadística, tasa por la expedición de pasaportes, por el reconocimiento, autorizaciones y concursos, etc.), son elevadas así al rango de ley formal.

45 En la redacción que se ofrece en la Ley 50/1998, de 30 de diciembre, y que ha ampliado este plazo en tres meses, del 1 de enero al 1 de de abril de 1999, Disposición Transitoria $11{ }^{2}$ 
quen las correspondientes Ordenanzas fiscales «al objeto de poder exigir tasas con arreglo a las modificaciones introducidas por la presente Ley»; pero efectúa otra manifestación realmente curiosa: «Entre tanto, $y$ hasta la fecha indicada, las Entidades locales podrán continuar exigiendo tasas y precios públicos con arreglo a la normativa anterior».

Antes de abordar el estudio del contenido de esta normativa, nos parece oportuno referirnos al alcance de este precepto jurídico. Cuando el legislador estatal otorga este plazo de adecuación de una legislación anterior, no sólo está exigiendo la adecuación de las correspondientes Ordenanzas fiscales que antes configuraban los «precios públicos» que ahora deben ser consideradas como «tasas», por su carácter de prestaciones patrimoniales de carácter público, sino que, implícitamente, está exigiendo que tal adecuación se efectúe siguiendo el procedimiento legalmente establecido.

Esto es, la nueva ley no sólo exige que las Entidades locales aprueben y publiquen los «acuerdos precisos de imposición y ordenación de tributos al objeto de poder exigir tasas con arreglo a las modificaciones introducidas por la presente ley en la Sección $3 .^{a}$ del Capitulo III del Título I de la Ley 39/1988, de 28 de diciembre», sino que ello se realice de la forma prevista en los artículos 15 a 19 de la Ley de Haciendas locales, Sección 2. ${ }^{a}$ del Capítulo III del Título I ${ }^{46}$, y por el único órgano competente para ello, el Pleno ${ }^{47}$.

En cuanto a esta regulación normativa, la solución jurídica adoptada nos parece cuestionable, al menos. Así, y ya refiriéndonos al párrafo $2 .^{\circ}$, de esta Disposición Transitoria 2. ${ }^{a}$, podemos afirmar que, en primer lugar, esta regulación de la situación jurídica anterior significa intentar situar al legislador estatal en el papel de los jueces, e incluso del propio Tribunal Constitucional, quienes deberán ser los que determinen la legalidad o no de la citada normativa (con la consiguiente confusión de funciones constitucionales que ello significa); pero es que, en segundo lugar, tal declaración es innecesaria, puesto que esta regulación será válida y eficaz mientras no sea declarada nula por el Tribunal Constitucional, respecto

\footnotetext{
46 Como ya nos advierte, antes incluso de la publicación de la Ley de Tasas de 1998, la Sentencia del Tribunal Supremo de fecha 27 de septiembre de 1997, al afirmar que los ingresos tributarios de las Entidades locales que no sean precios públicos, y se integren en el concepto de «prestación patrimonial de carácter público quedarán sometidos al principio de reserva de ley, y en consecuencia serán de observancia en el caso las prevenciones establecidas para la imposición y ordenación de los tributos municipales en los artículos 15 y siguientes de la Ley de Haciendas locales».

${ }^{47}$ FJ XVIII de la Sentencia del Tribunal Constitucional de fecha 16 de diciembre de 1999, como ya se ha visto anteriormente, vid. nota 21 .
} 
de la normativa de la Ley de Haciendas locales (como así ha sucedido, a excepción del art. 45.1), o por los Tribunales ordinarios, respecto a las Ordenanzas fiscales.

Y es que la situación jurídica de la normativa fiscal anterior será la que resulte de la aplicación de las técnicas propias de la hermenéutica, y no de ninguna declaración a posteriori del legislador.

\section{B) La relación interordinamental en materia de tasas locales}

No nos puede pues resultar excesivo afirmar que la Ley $25 / 1998$ ha sentado el criterio legislativo siguiente: la función y significado del principio de legalidad tributaria son cumplidos respecto de las tasas estatales por una norma jurídica con el rango de ley; mientras que, en lo que respecta a las tasas locales, este principio constitucional es cumplido por la colaboración entre la ley estatal y las normas reglamentarias locales (Ordenanzas fiscales).

De esta forma, y como hemos comprobado en el apartado anterior, esta ley permite a las Entidades locales establecer las diversas tasas locales, así como varios de sus elementos esenciales: hecho imponible y cuantía (cuota tributaria). Pero esta actuación no puede ser calificada como una actuación de deslegalización, en la que la ley se remita en bloque a una norma reglamentaria, sino como resultado de otra función, sin duda bastante más compleja.

La norma estatal procede sólo a la regulación de una parte de la materia normada, fijando un conjunto de límites indisponibles para la posterior regulación local (determina el concepto de tasa, regula un elemento de ésta - los sujetos pasivos-, y limita la regulación local en aspectos básicos tales como la prohibición de gravar determinados servicios públicos o los procedimientos de la cuantificación de las diversas tasas), pero deja el resto de la regulación de la materia tributaria, que es sin duda muy amplia, a las Ordenanzas fiscales que deban ser dictadas por las Entidades locales.

Así, y en lo que hace referencia a esta competencia compartida, el «subsistema normativo estatal» regula aquellos aspectos de la materia que entiende son competencia propia, referidos básicamente al cumplimiento de intereses generales, $\mathrm{y}$, autolimitándose en su función normado$\mathrm{ra}$, se remite a la futura y necesaria normativa local, para que se entienda 
regulada completamente esta materia, en los aspectos que entiende que son del ámbito propio de los intereses locales.

La situación de la norma estatal, Ley, con la norma local, Ordenanza fiscal, no es la propia de la jerarquía normativa, sino la propia de dos normas que en el ámbito de sus respectivas competencias se «complementan» para alcanzar, con su aplicación simultánea, la regulación de la materia compartida: tasas locales ${ }^{48}$.

\section{A MODO DE CONCLUSIÓN}

Compartimos el criterio legislativo de ampliar al máximo el ámbito de actuación de las Entidades locales en esta materia de las tasas locales. Para ello el legislador no ha dudado en aplicar la siguiente técnica normativa: la ley estatal y el reglamento local se «complementan» para la regulación de una misma materia, y ello para el cumplimiento del principio constitucional de reserva de ley; se huye así de la técnica lineal de la jerarquía y se potencia la actuación normativa de las Entidades locales.

Técnica y contenido legislativo que hoy podemos afirmar, por fin, que es plenamente constitucional.

\footnotetext{
${ }^{48}$ Conclusión jurídica que, aun en otra materia distinta a ésta como es la «autoorganización», no parece extraña a la jurisprudencia del Tribunal Supremo, cuando en su Sentencia de fecha 24 de septiembre de 1997 señala que ula Constitución española garantiza la autonomía de las entidades locales (art. 14 de la CE); por ello, la potestad reglamentaria resulta consustancial al reconocimiento constitucional de la autonomía de aquéllas. Quiere ello decir que los reglamentos locales gozan de primacía derivada de la competencia que la Ley atribuye a las Entidades locales, de suerte que la jerarquía carece de significado».
} 
REAL-1999, núm. 280-281. BELLO PAREDES, SANTIAGO A.. LA RESERVA DE LEY EN EL ÁMB...

REAL-1999, núm. 280-281. BELLO PAREDES, SANTIAGO A.. LA RESERVA DE LEY EN EL ÁMB... 